\title{
ARTICLE
}

\section{Nitrous acid-driven reduction of vanadium as a neptunium analogue}

\author{
Michael Chimes ${ }^{\mathrm{a}}$, Colin Boxall ${ }^{\mathrm{a}^{*}}$, Scott Edwards ${ }^{\mathrm{a}}$, Mark Sarsfield ${ }^{\mathrm{b}}$, Robin J. Taylor ${ }^{\mathrm{b}}$ and Dave Woodhead ${ }^{\mathrm{b}}$ \\ ${ }^{a}$ Engineering Department, Lancaster University, Gillow Avenue, Lancaster, England, LA1 $4 Y W ;{ }^{b}$ Central Laboratory, National \\ Nuclear Laboratory, Sellafield, Seascale, CA20 1PG, U.K.
}

\begin{abstract}
Neptunium has been previously shown to present challenges within a used nuclear fuel reprocessing scheme due to its tendency to exist in the (IV), (V), and (VI) oxidation states simultaneously. In order to control this neptunium speciation, and informed by relevant work in the literature, we are currently engaged in a study of nitric/nitrous acid redox chemistry with $\mathrm{Np}(\mathrm{V})$ and $\mathrm{Np}(\mathrm{VI})$. To minimize radiological exposure risks, we are also exploring the validity of using vanadium as an analogue for the study of the kinetics of the $\mathrm{Np}(\mathrm{VI}) / \mathrm{Np}(\mathrm{V})$ reduction by nitrous acid. The kinetics of the reduction of vanadium(V) by nitrous acid in solutions of nitric acid was investigated spectrophotometrically by the method of initial rates. Orders of reaction with respect to $\mathrm{V}(\mathrm{V})$, and $\mathrm{HNO}_{2}$ were found to be 0.90 , and 1.24 respectively, in reasonable agreement with the analogous reaction orders for the reduction of $\mathrm{Np}(\mathrm{VI})$ by nitrous acid previously reported by Precek and Paulenova suggesting that, for this particular reduction, $\mathrm{V}(\mathrm{V})$ can serve as a good kinetic analogue for $\mathrm{Np}(\mathrm{VI})$. The value of the rate constant $\mathrm{k}$ for the rate law $-\mathrm{d}[\mathrm{V}(\mathrm{V})] / \mathrm{dt}=\mathrm{k}[\mathrm{V}(\mathrm{V})]\left[\mathrm{HNO}_{2}\right]^{1.24} /\left[\mathrm{H}^{+}\right]$was found to be $7.5 \times 10^{-4} \mathrm{M}^{-0.24}$ $\mathrm{s}^{-1}$ at $20^{\circ} \mathrm{C}$, two orders of magnitude smaller than that for the reduction of $\mathrm{Np}(\mathrm{VI})$ by $\mathrm{HNO}_{2}$, a difference that is attributable to the loss of one of the oxygens during the $\mathrm{VO}_{2}^{+}$to $\mathrm{VO}^{2+}$ reduction reaction.
\end{abstract}

Keywords: neptunium; nitrous acid; vanadium; analogue; reduction; kinetics

\section{Introduction}

Currently, commercial reprocessing is largely done using the PUREX process in which extraction of tetravalent and hexavalent actinides is done by using tributyl phosphate (TBP) [1]. Neptunium is the cause of one particular challenge in the context of this process due to its capacity to be present simultaneously as the (IV), (V), and (VI) oxidation states in the aqueous phase as shown in speciation diagrams,[2] with (IV) existing as the free $\mathrm{Np}^{4+}$ ion and (V) and (VI) existing as the $\mathrm{NpO}_{2}{ }^{+}$and $\mathrm{NpO}_{2}{ }^{2+}$ respectively. The differing extractability of these oxidation states causes neptunium to be split across the organic and aqueous phases, with up to approximately $34 \%$ of $\mathrm{Np}$ entering the initial extraction cycle routed to the high activity raffinate [3, 4].

The key to controlling the routing of neptunium has been found to be to control the equilibrium between the $\mathrm{Np}(\mathrm{V})$ and $\mathrm{Np}(\mathrm{VI})$, seen in Eq. (1).

$$
\mathrm{NpO}_{2}^{+}+\frac{1}{2} \mathrm{NO}_{3}^{-}+\frac{3}{2} \mathrm{H}^{+} \rightleftharpoons \mathrm{NpO}_{2}^{2+}+\frac{1}{2} \mathrm{HNO}_{2}+\frac{1}{2} \mathrm{H}_{2} \mathrm{O}
$$

This reaction has been shown to have complex behaviour due to the twin roles of nitrous acid [5-8]. Especially at higher concentrations of nitrous acid, it has

*Corresponding author. Email: c.boxall@lancaster.ac.uk been shown to drive the reaction thermodynamically to the left, causing more neptunium to be in the pentavalent state at equilibrium. However, at low concentrations, nitrous acid has been seen to catalyse the oxidation reaction of $\mathrm{Np}(\mathrm{V})$ by nitric acid.

Previous studies on both the forward-going oxidation and reverse reduction reactions have yielded kinetic expressions as follows in Eq. (2) and (3), where $\mathrm{k}_{\mathrm{f}}$ and $\mathrm{k}_{\mathrm{b}}$ are rate constants for the forward and backward reactions respectively $[5,7,9-11]$. However, in trying to fit experimental data to models using these equations it has been found that the equations may be incomplete [10, 12] and therefore further investigation into these reactions is needed.

$$
\begin{aligned}
& -\frac{\mathrm{d}[\mathrm{Np}(\mathrm{V})]}{\mathrm{dt}}=k_{f} \frac{[\mathrm{Np}(\mathrm{V})]\left[\mathrm{H}^{+}\right]\left[\mathrm{HNO}_{2}\right]\left[\mathrm{NO}_{3}{ }^{-}\right]}{\left(k_{\alpha}[\mathrm{Np}(\mathrm{V})]+\left[\mathrm{HNO}_{2}\right]\right)} \\
& -\frac{\mathrm{d}[\mathrm{Np}(\mathrm{VI})]}{\mathrm{dt}}=k_{b} \frac{[\mathrm{Np}(\mathrm{VI})]\left[\mathrm{HNO}_{2}\right]^{1.2}}{\left[\mathrm{H}^{+}\right]}
\end{aligned}
$$

Our current focus is the reverse reduction reaction of $\mathrm{Np}(\mathrm{VI})$ to $\mathrm{Np}(\mathrm{V})$ by $\mathrm{HNO}_{2}$. Whilst the $\mathrm{Np}(\mathrm{VI}) / \mathrm{HNO}_{2}$ system has been studied in a seminal paper by Precek and Paulenova [11], it has never been studied in the context of $\mathrm{Np}(\mathrm{VI})$ that has been generated in situ from $\mathrm{Np}(\mathrm{V})$. Such a system may be complicated by the presence of nitrogen/oxygen intermediate species that are produced during the oxidative generation of $\mathrm{Np}(\mathrm{VI})$ 
from $\mathrm{Np}(\mathrm{V})$. Study of the effect of these nitrogen/oxygen species - a major constituent of which, as well as $\mathrm{HNO}_{2}$, has been postulated to be $\mathrm{NO}[10]-$ is the long-term objective of this work.

To minimize radiological exposure risks associated with using neptunium in investigation of the redox reaction of $\mathrm{Np}(\mathrm{VI})$ with nitrogen oxide species, the use of vanadium(V) as a $\mathrm{Np}(\mathrm{VI})$ analogue was investigated, beginning with the $\mathrm{V}(\mathrm{V}) / \mathrm{HNO}_{2}$ system as an analogue for the $\mathrm{Np}(\mathrm{VI}) / \mathrm{HNO}_{2}$ system that was well characterised by Precek and Paulenova [11]. Subsequent work will be extended to the $\mathrm{V}(\mathrm{V}) / \mathrm{NO}$ system.

Vanadium(V) was chosen as an analogue due to it showing a similar electrochemical potential for the $\mathrm{VO}_{2}{ }^{+} / \mathrm{VO}^{2+}$ couple as that of the $\mathrm{NpO}_{2}{ }^{2+} / \mathrm{NpO}_{2}{ }^{+}$couple [13]. In comparing these electrochemical potentials with those of the various nitrogen oxide standard potentials we can predict that the $\mathrm{V}(\mathrm{V})$ should be reduced in a similar manner to $\mathrm{Np}(\mathrm{VI})$ by nitrous acid, Figure 1.

Another reason for using vanadium was the structural similarities, with $\mathrm{V}(\mathrm{V})$ showing formation of the pervanadyl ion containing two oxygens, much like the formation of the neptunyl ion - although, unlike the neptunyl oxygens, the $\mathrm{O}-\mathrm{V}-\mathrm{O}$ bond has been shown to be bent, with bond angles ranging from $104^{\circ}$ to $107^{\circ}$.[14] Some differences can be expected in the respective rates of reduction of $\mathrm{V}(\mathrm{V})$ to $\mathrm{V}(\mathrm{IV})$ and $\mathrm{Np}(\mathrm{VI})$ to $\mathrm{Np}(\mathrm{V})$ due to breaking of a metal oxygen bond in the former reaction but not the latter.

\section{$\mathrm{E}_{0} \quad$ Half Reaction vs NHE}

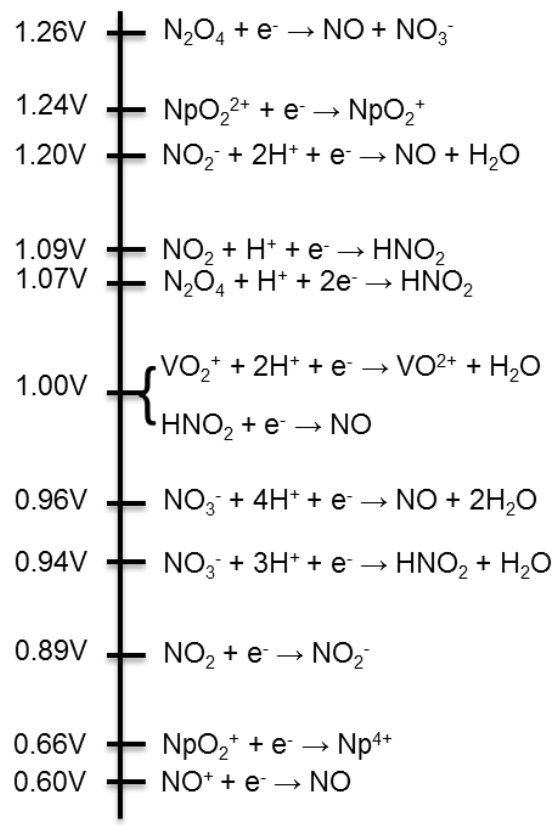

Figure 1. Redox ladder showing standard reduction potentials against a normal hydrogen electrode (NHE) for relevant neptunium, vanadium, and nitrogen oxide reductions.

\section{Experimental}

\subsection{Chemicals}

Vanadium (V) was prepared by dissolution of $\mathrm{NaVO}_{3}$ (Sigma-Aldrich, 98\%) in nitric acid. Solutions of nitrous acid were prepared by dissolution of sodium nitrite (Sigma-Aldrich) in nitric acid, where the nitrite anions where immediately protonated due to it being a relatively weak acid. Nitrous acid was prepared daily in order to minimize decomposition. $68 \%$ nitric acid (Sigma-Aldrich) was used for preparation of all $\mathrm{HNO}_{3}$ solutions. Distilled deionized water $(18 \mathrm{M} \Omega \mathrm{cm}$ resistivity) was used in all experiments.

\subsection{Instrumentation}

A wide UV-VIS-NIR range of 300-1,000 nm was monitored by an OceanOptics ${ }^{\mathrm{TM}}$ HR2000 spectrophotometer (fiber optic system) with combined deuterium/ halogen light source DH-2000 BAL. This allowed for the recording of absorbance on all selected wavelength within the $300-1,000 \mathrm{~nm}$ range simultaneously. Before each experimental run, a background was run of the correct $\mathrm{HNO}_{3}$ concentration and this background was then subtracted. To minimize noise, each spectrum was taken by averaging 5 successive scans and boxcar smoothing was employed for each absorbance measurement.

Full spectral scans were recorded before each experimental run, and compared with Choi et. al. [15] in order to check for the presence of $\mathrm{VO}^{2+}$ prior to the experimental run.

\subsection{Method and data analysis}

For varying $\mathrm{V}(\mathrm{V})$ and varying nitrite experiments, separate solutions of $\mathrm{NaVO}_{3}$ and $\mathrm{NaNO}_{2}$ were made up in $0.1 \mathrm{M} \mathrm{HNO}_{3}$ and mixed together in a cuvette in different ratios to give the required concentration of each.

The reaction was then monitored over the course of 15 hours by recording the full spectral range at intervals of 30 minutes. The extent of reaction could therefore be seen by looking at the increase in the V(IV) peak (the molar absorption coefficient value of V(IV) at $760 \mathrm{~nm}$ is $\varepsilon=17.17 \mathrm{M}^{-1} \mathrm{~cm}^{-1}[16]$ ), Figure 2 .

Plots were made of absorption at $769.67 \mathrm{~nm}$ vs time (Figure 3) and initial rate was calculated using the first 90 minutes of data points and fitting a slope of least squares linear regression. The gradients of these slopes were then used to plot log-log plots to give the order of reaction with respect to a given reactant. Rate constants were then also calculated using these reaction orders. Errors in these plots were determined by looking at the errors in baseline measurements along with pipetting and weight errors in order to give an error for each point. 


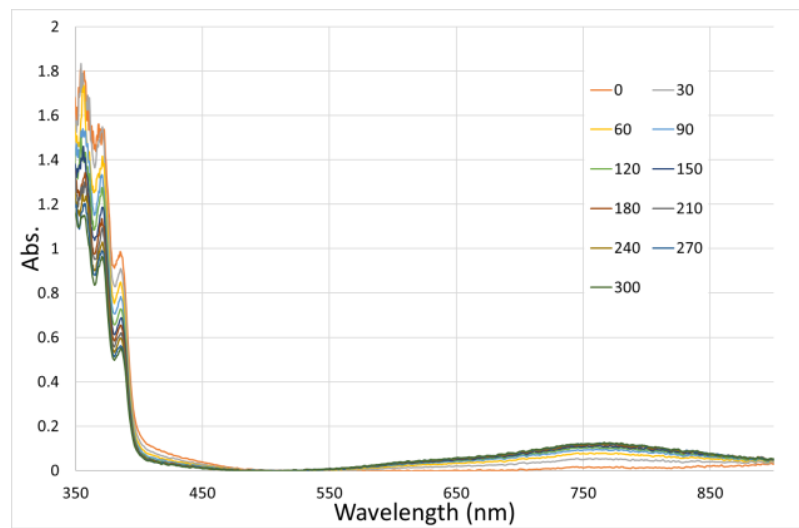

Figure 2. Spectral change for the $\mathrm{V}(\mathrm{V})$ reduction by $\mathrm{HNO}_{2}$ every 30 mins over the course of 5 hours. Over this time we see a decrease in the abs at approx. $385 \mathrm{~nm}$ due to loss of $\mathrm{V}(\mathrm{V})$ and nitrite and increase in the $\mathrm{V}(\mathrm{IV})$ peak at $760 \mathrm{~nm}$.

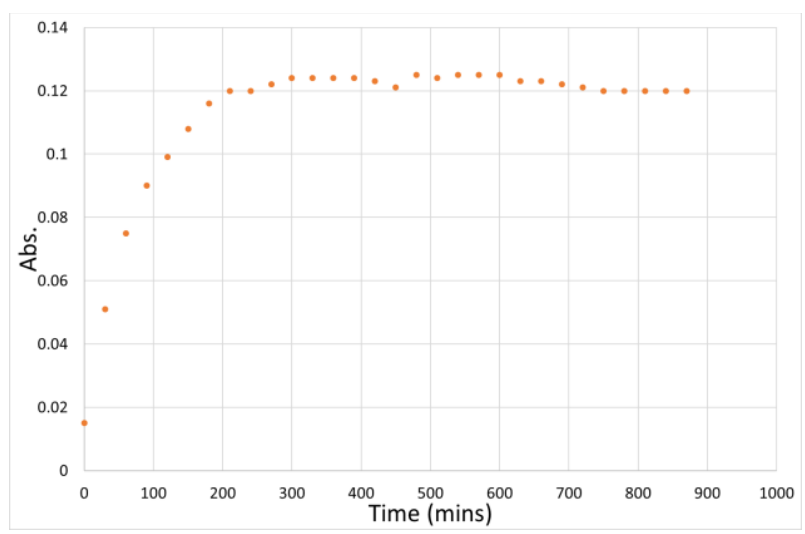

Figure 3. Plot of absorption at $767.97 \mathrm{~nm}$ vs time for the reduction of $10 \mathrm{mM} \mathrm{V(V)}$ by $25 \mathrm{mM} \mathrm{HNO}_{2}$.

\section{Results and discussion}

\subsection{Determination of reaction orders with respect to $\mathrm{V}(\mathrm{V})$ and $\mathrm{HNO}_{2}$}

Increases in either the initial $\mathrm{V}(\mathrm{V})$ or $\mathrm{HNO}_{2}$ concentrations lead to an increase in the initial reaction rate. Reaction order with respect to each of these reactants were found from the slope of the plot of $\log$ (rate) vs. $\log$ (initial reactant concentration), Figure 4.

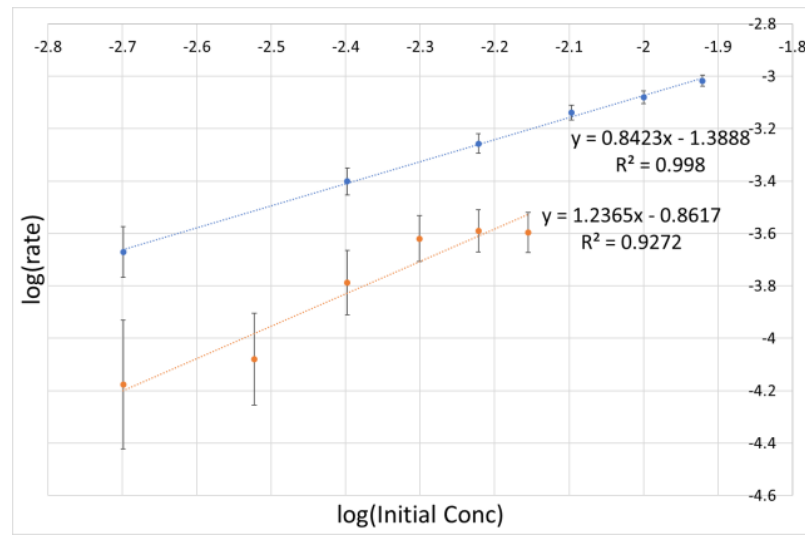

Figure 4. Determination of reaction orders with respect to $\mathrm{V}(\mathrm{V})$ and $\mathrm{HNO}_{2}$. (initial conditions: $0.1 \mathrm{M} \mathrm{HNO}_{3}$; blue circles $\mathrm{C}_{\mathrm{HNO} 2}=25 \mathrm{mM}, \mathrm{C}_{\mathrm{V}(\mathrm{V})}=2-12 \mathrm{mM}$; orange circles $\mathrm{CV}_{(\mathrm{V})}=$ $\left.15 \mathrm{mM}, \mathrm{C}_{\mathrm{HNO} 2}=2-7 \mathrm{mM}\right)$.
From this analysis, reaction orders with respect to $\mathrm{V}(\mathrm{V})$ and $\mathrm{HNO}_{2}$ were found to be 0.84 and 1.24 respectively, with the trendlines being seen to go through all appropriate error bars. Potential cation-cation interactions of the vanadium at higher concentrations have been considered to account for any deviation from linear behavior in varying $\mathrm{HNO}_{2}$ experiments. While cation-cation interactions are well known for both V(IV) and $\mathrm{V}(\mathrm{V})$ species in solution at higher acidities, [17] the acidities used in this study would not be expected to form cation-cation complexes. This is supported by the shape of the V(IV) peak present in our UV-vis spectra being comparable to that of the mononuclear cation.[18] The reaction orders are therefore in good agreement with the reaction orders of 1 and 1.2 found for $\mathrm{Np}(\mathrm{VI})$ and $\mathrm{HNO}_{2}$ by Precek \& Paulenova in their study of the reduction of $\mathrm{Np}$ by $\mathrm{HNO}_{2}$ [11] suggesting that a similar mechanism operates in both systems.

\subsection{Discussion on the mechanism of reaction}

Precek and Paulenova have reported the rate equation for the reduction of $\mathrm{Np}(\mathrm{VI})$ by $\mathrm{HNO}_{2}$ to be given by Eq.3 above [11]. From this and the similarities in reaction orders for the $\mathrm{V}(\mathrm{V}) / \mathrm{HNO}_{2}$ and $\mathrm{Np}(\mathrm{VI}) / \mathrm{HNO}_{2}$ systems noted above, we can deduce a similar form for the rate equation for the reduction of vanadium, Eq. (4), where $\mathrm{k}$ is the rate constant for the reaction.

$$
-\frac{\mathrm{d}[\mathrm{V}(\mathrm{V})]}{\mathrm{dt}}=k \frac{[\mathrm{V}(\mathrm{V})]\left[\mathrm{HNO}_{2}\right]^{1.24}}{\left[\mathrm{H}^{+}\right]}
$$

Using this equation, a value of the rate parameter $k$ can be calculated from the initial rate data of Figure 2. This is found to be $k=7.5 \times 10^{-4} \mathrm{M}^{-0.24} \mathrm{~s}^{-1}$ at $20{ }^{\circ} \mathrm{C}$ for the $\mathrm{V}(\mathrm{V}) / \mathrm{HNO}_{2}$ system, at value that is about two orders of magnitude smaller than that given by Precek \& Paulenova of $\mathrm{k}=0.159 \mathrm{M}^{-0.2} \mathrm{~s}^{-1}$ for the analogous $\mathrm{Np}$ (VI) reduction. This difference is likely due to the loss of an oxygen occurring during the vanadium reduction from the $\mathrm{VO}_{2}{ }^{+}$ion to the $\mathrm{VO}^{2+}$ ion alluded to earlier.

The mechanism for the reduction of $\mathrm{Np}(\mathrm{VI})$ by $\mathrm{HNO}_{2}$ has previously been proposed by Precek \& Paulenova [11], in agreement with Shilin \& Nazarov [8], to proceed via two pathways, as shown in Eq. (5-7).

Pathway 1:

$\mathrm{NpO}_{2}{ }^{2+}+\mathrm{NO}_{2}{ }^{-} \rightleftharpoons \mathrm{NpO}_{2}{ }^{+}+\mathrm{NO}_{2}$

Pathway 2:

$$
\begin{aligned}
& \mathrm{NpO}_{2}{ }^{2+}+\mathrm{NO} \rightleftharpoons \mathrm{NpO}_{2} \cdot \mathrm{NO}^{2+} \\
& \mathrm{NpO}_{2} \cdot \mathrm{NO}^{2+}+\mathrm{H}_{2} \mathrm{O} \rightleftharpoons \mathrm{NpO}_{2}{ }^{+}+\mathrm{HNO}_{2}+\mathrm{H}^{+}
\end{aligned}
$$

Based on the similarity between the rate equations for the $\mathrm{Np}(\mathrm{VI})$ and $\mathrm{V}(\mathrm{V})$ reduction deduced above, the mechanism for the reduction of vanadium by nitrous acid can be proposed to be as follows, Eq. (8-10), using the mechanism given for the neptunium reduction along with the standard reduction half equations given in Bard et. al. [13]. 
Pathway 1:

$$
\mathrm{VO}_{2}{ }^{+}+\mathrm{NO}_{2}{ }^{-}+2 \mathrm{H}^{+} \rightleftharpoons \mathrm{VO}^{2+}+\mathrm{NO}_{2}+\mathrm{H}_{2} \mathrm{O}
$$

Pathway 2:

$$
\begin{aligned}
& \mathrm{VO}_{2}^{+}+\mathrm{NO} \rightleftharpoons \mathrm{VO}_{2} \cdot \mathrm{NO}^{+} \\
& \mathrm{VO}_{2} \cdot \mathrm{NO}^{+}+\mathrm{H}^{+} \rightleftharpoons \mathrm{VO}^{2+}+\mathrm{HNO}_{2}
\end{aligned}
$$

\section{Conclusion}

The use of the $\mathrm{V}(\mathrm{V})$ reduction as an analogue for the reduction of $\mathrm{Np}(\mathrm{VI})$ by nitrous acid in a nitrate medium has been shown to give reaction orders with respect to the concentrations of $\mathrm{V}(\mathrm{V})$, and $\mathrm{HNO}_{2}$ that are in reasonable agreement with the analogous reaction orders for the reduction of $\mathrm{Np}(\mathrm{VI})$ by nitrous acid previously reported by Precek \& Paulenova [11] - suggesting that, for this particular reduction, $\mathrm{V}(\mathrm{V})$ can serve as a good mechanistic analogue for $\mathrm{Np}(\mathrm{VI})$. The rate parameter for the reduction of $\mathrm{V}(\mathrm{V})$ by nitrous acid is found to be two orders of magnitude smaller than that for the reduction of $\mathrm{Np}(\mathrm{VI})$ by $\mathrm{HNO}_{2}$, a difference that is attributable to the loss of one of the oxygens during the $\mathrm{VO}_{2}{ }^{+}$to $\mathrm{VO}^{2+}$ reduction reaction. Thus, the $\mathrm{V}(\mathrm{V}) / \mathrm{HNO}_{2}$ system can be considered a good mechanistic, albeit kinetically slower analogue for the $\mathrm{Np}(\mathrm{VI}) / \mathrm{HNO}_{2}$ and its use as such should always take account of this limitation.

\section{Acknowledgements}

MC is supported by both the EPSRC (via a "Next Generation Nuclear" Centre for Doctoral Training PhD studentship) and the Lloyds Register Foundation (LRF). CB is also supported by the LRF. The LRF supports the advancement of engineering-related education, and funds research and development that enhances safety of life at sea, on land and in the air.

\section{References}

[1] G. Choppin, J.-O. Liljenzin, J. Rydberg and C. Ekberg, (2013), The nuclear fuel cycle, radiochemistry and nuclear chemistry, 4 ed. Elsevier, pp. 685-751.

[2] K. Takao, S. Takao, A.C. Scheinost, G. Bernhard and C. Hennig, Formation of soluble hexanuclear neptunium(IV) nanoclusters in aqueous solution: growth termination of actinide(IV) hydrous oxides by carboxylates, Inorg. Chem., (2012), 51, pp.1336-1344.

[3] C.V. Roube, J.E. Birkett, G. Crooks, D. Fox, C.J. Maher and D.A. Woodhead, (2005), Investigations into $\mathrm{Np}$ routing in THORP HA/HS, Nexia Solutions 5918.

[4] R.S. Herbst, P. Baron, and M. Nilsson, (2011), Standard and advanced separation: PUREX processes for nuclear fuel reprocessing, Advanced Separation Techniques for Nuclear Fuel Reprocessing and Radioactive Waste Treatment. Elsevier Science, pp. 141-175.

[5] O. Tochiyama, Y. Nakamura, M. Hirota and Y. Inoue, Kinetics of nitrous acid-catalyzed oxidation of neptunium in nitric acid-TBP extraction system,
J. Nucl. Sci. Technol., (1995), 32, pp.118-124.

[6] O. Tochiyama, Y. Nakamura, Y. Katayama and Y. Inoue, Equilibrium of nitrous acid-catalyzed oxidation of neptunium in nitric acid-TBP extraction system, J. Nucl. Sci. Technol., (1995), 32, pp.50-59.

[7] T.H. Siddall and E.K. Dukes, Kinetics of HNO2 catalyzed oxidation of neptunium(V) by aqueous solutions of nitric acid, J. Am. Chem. Soc., (1959), 81, pp.790-794.

[8] V. Koltunov, I. Shilin, V. Nazarov and G. Zhuravleva, (1968), Materialy simpoziuma SEV: Issledovania $\mathrm{v}$ oblasti pererabotki obluchennogo topliva, Proceedings of CMEA Symposium: Research in the area of the reprocessing of spent nuclear fuel, Karlovy Vary, Czechoslovak Socialist Republic.

[9] J.P. Moulin, (1978), Oxidation - reduction kinetics of neptunium in nitric acid solution, CEA-R-4912.

[10]H. Chen, R.J. Taylor, M. Jobson, D.A. Woodhead, C. Boxall, A.J. Masters and S. Edwards, Simulation of neptunium extraction in an advanced PUREX process-model improvement, Solvent Extr. Ion Exch., (2017), 35, pp.1-18.

[11]M. Precek and A. Paulenova, Kinetics of reduction of hexavalent neptunium by nitrous acid in solutions of nitric acid, J. Radioanal. Nucl. Chem., (2010), 286, 771-776.

[12]C. Gregson, C. Boxall, M. Carrott, S. Edwards, M. Sarsfield, R. Taylor and D. Woodhead, Neptunium (V) oxidation by nitrous acid in nitric acid, Procedia Chemistry, (2012), 7, pp.398-403.

[13]A.J. Bard, R. Parsons and J. Jordan, Standard Potentials in Aqueous Solution, Taylor \& Francis, (1985), ISBN 9780824772918.

[14]W.R. Scheidt, Crystallographic study of the structural trans effect. Molecular structure of oxoisopropoxobis(8-hydroxyquinolinato)vanadium (V), Inorg. Chem., (1973), 12, pp.1758-1761.

[15]N.H. Choi, S.-k. Kwon and H. Kim, Analysis of the oxidation of the $\mathrm{V}(\mathrm{II})$ by dissolved oxygen using UV-visible spectrophotometry in a vanadium redox flow battery, J. Electrochem. Soc., (2013), 160, pp.A973-979.

[16] R.P. Brooker, C.J. Bell, L.J. Bonville, H.R. Kunz and J.M. Fenton, Determining vanadium concentrations using the UV-vis response method, J. Electrochem. Soc., (2015), 162, pp.A608-613.

[17]P. Blanc, C. Madic and J.P. Launay, Spectrophotometric identification of a mixed-valence cation-cation complex between aquadioxovanadium(V) and aquaoxovanadium(IV) ions in perchloric, sulfuric, and hydrochloric acid media, Inorg. Chem., (1982), 21, pp.2923-2928.

[18]X. Wu, J. Wang, S. Liu, X. Wu and S. Li, Study of vanadium(IV) species and corresponding electrochemical performance in concentrated sulfuric acid media, Electrochim. Acta, (2011), 56, pp.10197-10203. 